\title{
Redescrição e osteologia de Bryconamericus exodon Eigenmann, 1907 (Ostariophysi, Characiformes, Characidae)
}

\author{
Jane Piton Serra ${ }^{1,2}$ \& Francisco Langeani ${ }^{2}$
}

Biota Neotropica v6 (n3) -http://www.biotaneotropica.org.br/v6n3/pt/abstract?article+bn01906032006

\author{
Recebido em 19/04/05. \\ Versão revisada recebida em 03/07/06. \\ Publicado em 22/09/06
}

1,2 UNESP - Universidade Estadual Paulista (www.ibilce.unesp.br), Laboratório de Ictiologia, Departamento de Zoologia e Botânica, câmpus de São José do Rio Preto, rua Cristóvão Colombo 2265, 15054-000, São José do Rio Preto, SP, Brasil. (e-mail: pitonbio@yahoo.com.br, langeani@ibilce.unesp.br).

1 Correspondências para Jane Piton Serra pitonbio@yahoo.com.br

\begin{abstract}
Serra, J.P. and Langeani, F. Redescription and osteology of Bryconamericus exodon Eigenmann, 1907 (Ostariophysi, Characiformes, Characidae). Biota Neotrop. Sep/Dec 2006 vol. 6, no. 3 http://www.biotaneotropica.org.br/v6n3/pt/ abstract?article+bn01906032006 ISSN 1676-0603
\end{abstract}

The redescription of B. exodon Eigenmann (1907), type species of Bryconamericus, an osteological description for the species, a comparison with other characiform fishes, and comments about its relationships among other characids are presented. Bryconamericus exodon is easily distinguished from other species in the genus by possessing upper and lower caudal-fin lobes dark brown; it is proximate to other Bryconamericus species that possess: an elongated and low body, its depth less than $30 \%$ of standard length, mouth terminal, and teeth of external premaxillary series not aligned. Furthermore it shares with other Characidae a palatine fenestrate, perforated or shallowed in its medial, anterior, portion, and a third postcleithrum elongated and equally wide along its entire length, character states proposed as additional synapomorphies for the characids with ii, 8 dorsal-fin rays and four teeth in the internal premaxillary series.

Key words: palatine fenestra, teeth, premaxillary, third postcleithrum, dorsal-fin rays, color pattern

\section{Resumo}

Serra, J.P. and Langeani, F. Redescrição e osteologia de Bryconamericus exodon Eigenmann, 1907 (Ostariophysi, Characiformes, Characidae). Biota Neotrop. Sep/Dec 2006 vol. 6, no. 3 http://www.biotaneotropica.org.br/v6n3/pt/ abstract?article+bn01906032006 ISSN 1676-0603

Apresenta-se a redescrição de Bryconamericus exodon Eigenmann (1907), espécie-tipo do gênero, uma descrição osteológica da espécie, uma comparação com outras espécies de Characiformes e comentários sobre seu relacionamento com outros caracídeos. Bryconamericus exodon é facilmente distinta de todas as demais espécies do gênero por possuir os lobos superior e inferior da nadadeira caudal castanho-escuros; aproxima-se das espécies de Bryconamericus com corpo alongado e baixo, menos de 30\% do comprimento padrão, boca terminal e dentes da série externa do pré-maxilar desalinhados. Compartilha com outros Characidae um palatino fenestrado, perfurado ou adelgaçado, em sua porção médio-anterior, e um pós-cleitro 3 alongado e com aproximadamente a mesma largura em toda sua extensão, sinapomorfias adicionais para os Characidae com ii, 8 raios na nadadeira dorsal e quatro dentes na série interna do pré-maxilar.

Palavras-chave: fenestra palatina, dentes, pré-maxilar, pós-cleitro três, raios dorsais, padrão de colorido. 


\section{Introdução}

Characidae é uma família numerosa e heterogênea (Reis et al. 2003). Lima et al. (2003) relacionam como incertae sedis dentro da família 80 gêneros e mais de 600 espécies (muitas anteriormente classificadas em Tetragonopterinae sensu Géry, 1977), em vista do desconhecimento a respeito de seu monofiletismo e de suas relações filogenéticas. Dentre os gêneros incertae sedis de Characidae, há dois grupos que têm sido reconhecidos pela presença constante e invariável de quatro dentes na série interna do pré-maxilar: Piabina e Creagrutus, grupo monofilético com relações internas estabelecidas (Vari \& Harold 1998, 2001) e os "Hemibrycon and allied genera” (Géry 1966, 1977), com Boehlkea, Bryconacidnus, Bryconamericus, Carlastyanax, Coptobrycon, Hemibrycon, "Hyphessobrycon" melanopleurus, Knodus, Nematobrycon, Microgenys, Piabarchus, Rhinobrycon, Rhinopetitia, para os quais não havia nenhuma evidência de monofiletismo. Malabarba \& Weitzman (2003), entretanto, propõem que, dentre os Characidae com ganchos ósseos nos raios das nadadeiras e ausência de supra-orbital, a presença de quatro dentes na série interna do pré-maxilar e ii, 8 raios na nadadeira dorsal seja sinapomórfica para um grupo denominado de clado A (utilizado doravante no texto), composto por Glandulocaudinae, Creagrutus, Caiapobrycon, Piabina e os “Hemibrycon and allied genera” de Géry (1977), exceto Nematobrycon e Coptobrycon.

Dentro desse grupo, Bryconamericus é um dos gêneros com maior diversidade, compreendendo cerca de 50 espécies de tamanho pequeno, distribuídas desde a América Central até o oeste da Argentina (Lima et al. 2003). Na descrição original, Eigenmann (in Eigenmann, MacAtee \& Ward 1907) chama a atenção para o desalinhamento dos dentes da série externa do pré-maxilar. Posteriormente, Eigenmann (1927) caracteriza o gênero pela presença de linha lateral completa, nadadeira caudal nua, terceiro infra-orbital expandido e em contato com o pré-opérculo, e quatro dentes na série interna do pré-maxilar; Vari \& Siebert (1990) adicionam: maxilar com limitado número de dentes [até seis] ao longo de sua margem; rastros branquiais setiformes e ausência de glândula na nadadeira caudal.

Essa definição de Bryconamericus é muito ampla; mesmo Eigenmann (1927) já notava sua grande heterogeneidade e dividia o gênero em três ou quatro grupos "derivados independentemente a partir de diferentes espécies de Astyanax e Hemibrycon”. Vari \& Siebert (1990) comentam que "existe pouca confiança de que Bryconamericus represente um grupo monofilético dentro de Characidae”, no que concordam Malabarba \& Malabarba (1994). Román-Valencia (2000), ao contrário, afirma que o gênero é natural (incluindo Knodus e Eretmobrycon). A questão da sistemática de Bryconamericus e Knodus permanece, contudo, um problema complexo que necessita de maiores análises além daquelas usualmente desenvolvidas, relacionadas à morfometria, merística e anatomia superficial (Weitzman et al. 2005)
Apresentamos aqui a redescrição de Bryconamericus exodon, espécie tipo do gênero, uma descrição osteológica da espécie, uma comparação com outros táxons de Characidae com quatro dentes na série interna do pré-maxilar e ii, 8 raios dorsais, e comentários sobre seu relacionamento filogenético dentro de Characidae.

\section{Material e Métodos}

O material analisado pertence às seguintes coleções: The Academy of Natural Sciences of Philadelphia (ANSP), Departamento de Zoologia e Botânica de São José do Rio Preto (DZSJRP), Field Museum of Natural History (FMNH), Museu de Ciência e Tecnologia da Pontifícia Universidade Católica do Rio Grande do Sul (MCP), Museu de Zoologia da Universidade Estadual de Londrina (MZUEL), Museu de Zoologia da Universidade de São Paulo (MZUSP) e Núcleo de Pesquisas em Limnologia, Ictiologia e Aqüicultura da Universidade Estadual de Maringá (NUPELIA). Exemplares de espécies adicionais de Bryconamericus estão listados em Langeani et al. (2005)

Os exemplares foram submetidos a uma série de 18 contagens e 18 medidas segundo Fink \& Weitzman (1974), com as seguintes modificações: 1- a contagem de vértebras não inclui as 4 primeiras vértebras modificadas do Aparelho de Weber; 2- contagem de escamas cobrindo a base da nadadeira anal: representadas apenas pelas escamas que se pronunciam sobre os raios da nadadeira; 3- contagem de raios branquiostégios; 4 - altura da cabeça medida entre a base do processo occipital e o istmo; 5- distância interorbital: menor distância entre as margens ósseas superiores das órbitas; 6- distância pré-dorsal: da extremidade anterior do focinho até a origem da nadadeira dorsal; 7- distância pré-ventral: da extremidade anterior do focinho até a origem da nadadeira pélvica; 8- distância entre as nadadeiras pélvica e a anal: da porção posterior da base da nadadeira pélvica até a porção anterior da base da nadadeira anal. O comprimento padrão (CP) é expresso em milímetros e as demais medidas como porcentagens do comprimento padrão ou do comprimento da cabeça. Todas as medidas foram tomadas com paquímetro, de ponto a ponto, do lado esquerdo dos exemplares, sempre que possível, e com aproximação de décimos de mm. Uma análise estatística básica foi aplicada aos dados com o intuito de obter os valores mínimo e máximo, a média (para medidas) e a moda (para contagens) e o desvio padrão. As contagens de vértebras, rastros branquiais, raios branquiostégios e número total de dentes do dentário, foram feitas somente em material diafanizado e corado e nesses casos não é apresentada a moda.

Na redescrição, os valores entre parênteses são, respectivamente, a média ou a moda dos valores e o número total de exemplares analisados, separados por ponto e vírgula. 
Três exemplares de Byconamericus exodon de diferentes tamanhos (31; 43,1 e 47,5 mm) foram diafanizados e corados pelo método de Potthoff (1984) e dissecados de acordo com Weitzman (1974). Os conjuntos ósseos foram examinados e ilustrados sob estereomicroscópio equipado com câmara clara. As ilustrações dos conjuntos ósseos foram realizadas a partir do exemplar de 43,1mm, que apresentava melhor coloração. A nomenclatura osteológica segue basicamente Weitzman (1962), com modificações de Monod (1967, 1968), Fink \& Fink (1981) e Vari (1983), utilizadas segundo a tradução para a língua portuguesa proposta por Castro \& Castro (1987), mais as adições de “processo lateral do centro vertebral dois" e "processo transverso da terceira vértebra”.

Abreviações utilizadas nas figuras: aar - ângulo-articular; an - arco neural; ant - antorbital; bb - basibranquial; bh - basi-hial; boc - basioccipital; cb - ceratobranquial; cha cerato-hial anterior; chp - cerato-hial posterior; cla - claustro; cle - cleitro; cn - complexo neural; co - coracóide; $\mathbf{c p}$ - costela pleural; cv - centro vertebral; d - dentário; eb - epibranquial; ect - ectopterigóide; ef - escáfio; eh - espinho hemal; en espinho neural; ep - epural; epo - epoccipital; esc - escápula; esf - esfenótico; esp - esquírola pélvica; etl - etmóide lateral; exe - extra-escapular; exo - exoccipital; fb - faringobranquial; fc - fontanela craniana; fpt - fossa pós-temporal; fr - frontal; hb - hipobranquial; hi - hiomandibular; hip hipural; hp - hipial; i - infra-orbital; ic - intercalário; ih inter-hial; iop - interopéculo; mes - mesopterigóide; mese mesetmóide; meso - mesocoracóide; met - metapterigóide; mx - maxilar; na - nasal; ocm - osso corono-meckeliano; oe órbito-esfenóide; op - opérculo; ope - osso pélvico; pa parietal; pal - palatino; pc - pós-cleitro, pd - placa dentígera; pe - paresfenóide; pi - processo isquiático; plc - processo lateral do centro vertebral dois; pm - pré-maxilar; pne processo neural especializado; po - pró-ótico; pop - préopérculo; pp - paripural; prt - processo transverso da terceira vértebra; pt - pós-temporal; pte - pteroesfenóide; ptm - peça terminal; ptr - pterótico; qua - quadrado; rar retroarticular; rb - rastro branquial; rbr - raio branquiostégio; rd - radial distal; re - rinoesfenóide; rm - radial mediano; rp - radial proximal; rpc - raios procorrentes; scl - supracleitro; sim - simplético; sn - supraneural; soc - supra-occipital; sop - subopérculo; te - trabécula epifiseana; tr - trípode; uh uro-hial; un - uroneural; ur - uróstilo; vo - vômer.

A hipótese inicial para orientar a busca por características exclusivas e diagnósticas assumia o gênero Bryconamericus como monofilético, tendo como referência $B$. exodon, sua espécie-tipo. Todos os demais gêneros examinados foram considerados grupos externos separados em três níveis: $1^{\circ}$ - outros Characidae com quatro dentes na série interna do pré-maxilar e nadadeira dorsal com ii+8 raios (grupo considerado monofilético por Malabarba \& Weitzman 2003); $2^{\circ}$ - demais Characidae "Tetragonopterinae” (sensu Géry 1977); $3^{\circ}$ - outros Characiformes (Characidae e
Alestidae). Bryconamericus exodon, portanto, foi inicialmente comparado com os demais Bryconamericus; as diferenças entre eles foram assumidas como apomórficas ou plesiomórficas por meio de comparações com aqueles três níveis de grupos externos (v. Watrous \& Wheeler 1981) e, eventualmente, dados de literatura.

\section{Resultados}

\section{Redescrição}

Bryconamericus exodon Eigenmann, 1907

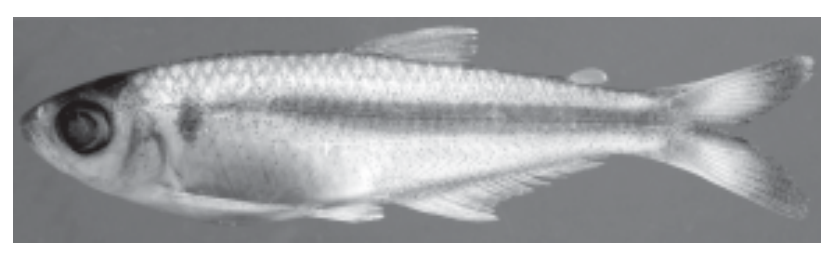

Fig. 1- Bryconamericus exodon, MZUSP 54010, 36,5 mm CP, Paraguay: Alto Paraguay, Fuerte Olimpo, rio Paraguay em frente à zona militar, na fronteira com o Brasil.

Fig. 1- Bryconamericus exodon, MZUSP 54010, 36,5 mm SL, Paraguay: Upper Paraguay, Fuerte Olimpo, Paraguay river in front of the military zone, boundary with Brazil.

\subsection{Material examinado}

Bryconamericus exodon: MZUSP 28026 (98 ex., CP 22-44 mm; 1d\&c. CP. 43,1 mm), BRASIL: MT, Poconé, rio Cuiabá (viveiro de pássaros), 16³0’S/56²4’W; MZUSP54017 (8 ex., CP 30-38 mm; 1d\&c. CP 31 mm), PARAGUAI: Alto Paraguay, riacho Miranda, estância Puerto Miranda, cerca de $5 \mathrm{Km}$ de Puerto Voluntad, 2040’0"S/ 5759’0"W; MZUSP 54010 (10 ex., CP 23,4-37 mm), PARAGUAY: Alto Paraguay, Fuerte Olimpo, rio Paraguay em frente a zona militar, na fronteira com o Brasil; MZUSP 54011 (1 ex., CP 46.6 mm), PARAGUAY: Concepcion, rio Apa, região das corredeiras, cerca de 2 horas de bote acima de San Carlos; MZUSP 53947 (2 ex., CP 36,8-38 mm), PARAGUAY: Concepcion, rio Apa, em região de corredeira; MZUSP 53948 (2 ex., CP 22,6-26,5 mm), PARAGUAY, Alto Paraguay, rio Paraguay, em um charco de água comunicando com o rio.

\subsection{Diagnose}

Bryconamericus exodon é facilmente diferenciada de todas as demais espécies do gênero por apresentar a porção distal dos lobos caudais superior e inferior castanho-escura (vs. porção distal dos lobos da nadadeira caudal hialina ou apenas levemente escurecida). A espécie é morfologicamente semelhante à $B$. stramineus por apresentar corpo relativamente baixo e alongado, sua altura menos de $30 \%$ do comprimento 
padrão (vs. mais de $30 \%$ do CP), boca terminal (vs. boca inferior) e série externa de dentes do pré-maxilar desalinhada (vs. série externa de dentes do pré-maxilar alinhada).

\subsection{Descrição}

Dados morfométricos na Tabela 1. Perfil dorsal do corpo convexo, da ponta do focinho até a origem da nadadeira dorsal, eventualmente mais retilíneo na região da cabeça; reto e descendente da origem da nadadeira dorsal até o final do pedúnculo caudal. Perfil ventral do corpo convexo, da ponta do focinho até a origem da nadadeira anal; reto e ascendente ao longo da nadadeira anal; reto do final da anal até o final do pedúnculo caudal.

Boca terminal. Maxila superior mais pronunciada anteriormente que a maxila inferior. Pré-maxilar com duas séries de dentes; externa com 4 a 6 dentes tricuspidados (4; 27); interna com 4 dentes tetra, penta ou hexacuspidados (4; 29). Série externa do pré-maxilar com dentes desalinhados; em exemplares com 4 dentes, o primeiro e o quarto são mais projetados anteriormente; em exemplares com 5 dentes, o primeiro e o quinto ou o primeiro, o terceiro e o quinto são mais projetados anteriormente; em exemplares com 6 dentes, o primeiro e o sexto ou o primeiro, o terceiro, o quinto e o sexto são mais projetados anteriormente. Maxilar com 2 ou 3 dentes, raramente um, tricuspidados, eventualmente cônicos (2; 28). Dentário com uma única série de 4 dentes anteriores e maiores $(4 ; 28)$, tetra, penta ou hexacuspidados, seguidos por 8 a 11 dentes tricuspidados ou cônicos menores (3).

Nadadeira dorsal com ii, 8 raios $(8 ; 30)$. Nadadeira peitoral com i, 10-12 raios (11; 30). Nadadeira pélvica com i, 7 raios, raramente i, 6 ou 8 raios $(7 ; 30)$. Nadadeira anal longa, com iii-iv, 20-24 raios (22; 29); sua origem aproximadamente na altura da vertical que passa pelo meio da base da nadadeira dorsal. Nadadeira anal com uma série de 4 a 6 escamas, raramente três ou sete $(5 ; 29)$, cobrindo a base dos primeiros raios. Nadadeira caudal com apenas algumas escamas cobrindo a base dos raios, com $10+9$ raios principais $(10+9$, 30). Raios das nadadeiras pélvica e anal dos machos com ganchos ósseos durante o período reprodutivo.

Linha lateral com 34 a 43 escamas perfuradas (39; 27); 4 a $6(5 ; 27)$ séries longitudinais de escamas acima da linha lateral e 3 a 5 (4; 27) séries longitudinais de escamas abaixo da linha lateral. Linha pré-dorsal com 11 a 14 escamas (12; 24). Trinta e três a trinta e quatro vértebras (3). Primeiro arco branquial com 2 a 3 rastros no hipobranquial, 7 a 9 rastros no ceratobranquial e 5 a 8 rastros no epibranquial, às vezes 1 rastro nas junções entre o hipobranquial e o ceratobranquial e entre esse e o epibranquial. Quatro raios branquiostégios.

\subsection{Coloração}

Corpo castanho claro; cromatóforos castanhoescuros densamente distribuídos nas regiões anterior e dorsal da cabeça, desde o focinho até o final do espinho supra-occipital; porção dorsal do corpo com uma grande concentração de cromatóforos, formando uma faixa relativamente estreita (menos de um terço do diâmetro orbital), escura e ininterrupta desde o final da cabeça até o final do pedúnculo caudal. Cromatóforos também distribuídos por todo o corpo, em menor concentração ou ausentes na região da cavidade visceral, especialmente concentrados na porção látero-dorsal do corpo. Mácula umeral bastante conspícua e verticalmente alongada, localizada na altura da vertical que passa pelo primeiro terço da nadadeira peitoral e estendendo-se verticalmente por cerca de 3 séries de escamas (a da linha lateral, uma acima e uma abaixo). Listra negra médio-lateral, começando pouco depois da mácula umeral, se estendendo ao longo da segunda série de escamas acima da linha lateral até o pedúnculo caudal; uma linha escura fina percorre a porção mediana de toda a listra negra médio-lateral. A listra médiolateral pode apresentar-se prateada, em função de uma maior presença de cristais de guanina impedindo a visualização dos cromatóforos. Sem mancha característica no pedúnculo caudal. Nadadeiras anal, dorsal e peitorais, e em menor quantidade as pélvicas, com cromatóforos dispersos. Nadadeira caudal com cromatóforos escuros ao longo da porção mediana e na porção distal dos lobos.

\subsection{Distribuição}

Bacia do rio Paraguai.

\section{Osteologia}

Não foram encontradas diferenças significativas entre os três espécimes de B. exodon analisados.

\subsection{Neurocrânio}

Mesetmóide com formato losangular em vista dorsal e duas projeções laterais; região anterior levemente curvada em direção ventral. Vômer bifurcado anteriormente; as bifurcações visíveis em vista dorsal, lateralmente ao mesetmóide. Frontal retangular; região anterior arredondada. Fontanela craniana ampla, do mesetmóide ao supra-occipital, separando completamente os frontais e parietais medianamente, exceto na barra epifiseal. Etmóide lateral bastante curto em vista ventral, com uma pequena projeção anterolateral, visível em vista dorsal. Processo lateral do esfenótico afilando e terminando em ponta arredondada, dirigida ventralmente. Pterótico com uma projeção lateral e posterior, muito pequena e arredondada. Epoccipital delgado, sua porção mediana, entre as duas fossas pós-temporais, bastante estreitada em vista lateral. Exoccipital com a região posterior ventral bastante desenvolvida. Basioccipital com a região anterior, próximo à região de contato entre o próótico e o exoccipital, alta, e mais baixo na região posterior. 
Serra, J.P. and Langeani, F. - Biota Neotropica, v6 (n3) - bn01906032006

Tabela 1- Morfometria de Bryconamericus exodon: comprimento padrão expresso em milímetros e demais medidas como porcentagens do comprimento padrão ou comprimento da cabeça.

Table 1-Morphometrics of Bryconamericus exodon: standard length (mm), other measurements as percentages of the standard length or head length

\begin{tabular}{lcccc}
\hline Caráter & N & Mínimo & Máximo & Média \\
\hline Comprimento Padrão $(\mathrm{mm})$ & 30 & 22,6 & 46,6 & 35,4 \\
\hline
\end{tabular}

Porcentagens do Comprimento Padrão

\begin{tabular}{llllll}
\hline Altura do Corpo & 30 & 21,2 & 27,3 & 23,6 & 1,3 \\
Comprimento da Cabeça & 30 & 22,8 & 28,5 & 24,4 & 1,0 \\
Distância Pré-Dorsal & 30 & 45,5 & 52,1 & 49,3 & 1,5 \\
Distância Pré-Ventral & 30 & 42,1 & 48,2 & 45,0 & 1,3 \\
Distância Pélvica - Anal & 30 & 11,3 & 16,8 & 14,0 & 1,5 \\
Altura do Pedúnculo Caudal & 30 & 9,0 & 11,0 & 10,0 & 0,5 \\
Comprimento do Pedúnculo Caudal & 30 & 11,3 & 16,3 & 13,2 & 1,2 \\
Comprimento da base da Dorsal & 30 & 10,6 & 14,7 & 12,3 & 0,9 \\
Comprimento da base da Anal & 30 & 28,9 & 33,4 & 30,7 & 1,2 \\
Comprimento da Peitoral & 30 & 16,3 & 31,0 & 19,7 & 2,4 \\
Comprimento da Pélvica & 30 & 10,9 & 15,4 & 12,6 & 0,9 \\
Comprimento da Dorsal & 30 & 20,4 & 25,3 & 22,8 & 1,3 \\
Comprimento da Anal & 30 & 15,1 & 20,7 & 18,4 & 1,4 \\
\hline
\end{tabular}

Porcentagens do Comprimento da Cabeça

\begin{tabular}{llllll}
\hline Altura da Cabeça & 30 & 71,2 & 88,1 & 77,1 & 4,2 \\
Diâmetro da Orbita & 30 & 38,3 & 47,3 & 42,3 & 2,4 \\
Comprimento do Focinho & 30 & 20,8 & 31,0 & 25,7 & 2,5 \\
Distância Interorbital & 30 & 28,2 & 45,2 & 33,3 & 3,0 \\
\hline
\end{tabular}

http://www.biotaneotropica.org.br 
Processo posterior do supra-occipital curto, não ultrapassando a vertical que passa pela porção posterior do basioccipital. Rinoesfenóide retangular, ligado ao órbitoesfenóide através de cartilagem delgada. Órbito-esfenóide com uma ampla região de contato com o frontal, uma porção anterior mais delgada e longa que contata o rinoesfenóide e uma leve constrição posterior, na região de contato com o pteroesfenóide. Pteroesfenóide com margem ventral ligeiramente côncava, em vista lateral, desde o órbitoesfenóide até a região de contato com esfenótico. Paresfenóide com leve curvatura, se estendendo até o basioccipital e terminando em uma bifurcação na altura da junção do basioccipital com o pterótico (Figs. 2-4).

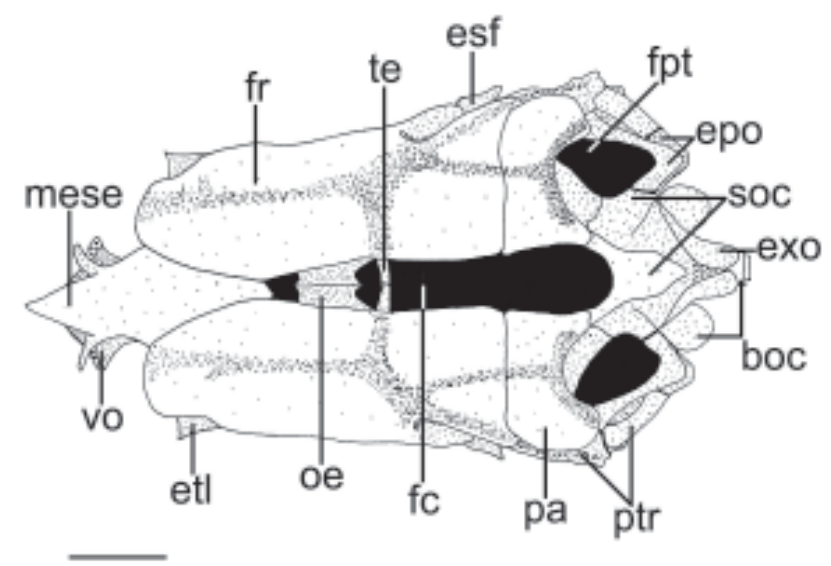

Fig. 2- Bryconamericus exodon, MZUSP 28026, 43,1 mm CP, vista dorsal do crânio. Escala, $1 \mathrm{~mm}$.

Fig. 2- Bryconamericus exodon, MZUSP 28026, 43,1 mm SL, cranium, dorsal view. Scale bar, $1 \mathrm{~mm}$.

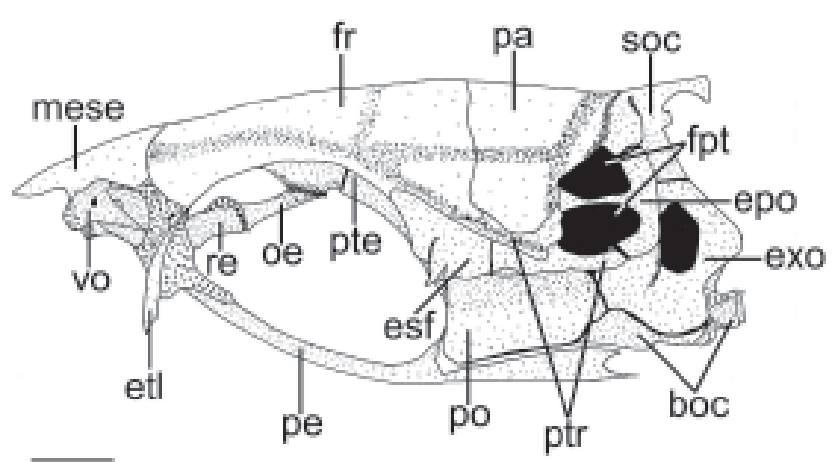

Fig. 3- Bryconamericus exodon, MZUSP 28026, 43,1 mm CP, vista lateral do crânio. Escala, $1 \mathrm{~mm}$.

Fig. 3- Bryconamericus exodon, MZUSP 28026, 43,1 mm SL, cranium, lateral view. Scale bar, $1 \mathrm{~mm}$.

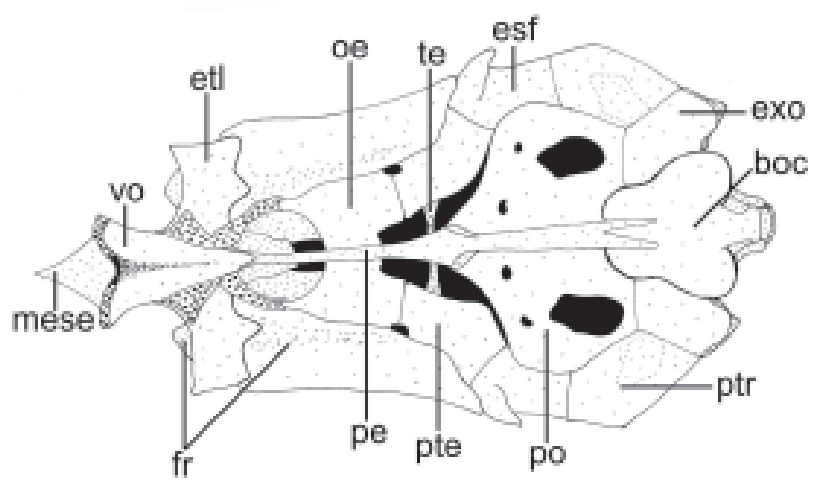

Fig. 4- Bryconamericus. exodon, MZUSP 28026, 43,1 mm CP, vista ventral do crânio. Escala, $1 \mathrm{~mm}$.

Fig. 4- Bryconamericus. exodon, MZUSP 28026, 43,1 mm SL, cranium, ventral view. Scale bar, $1 \mathrm{~mm}$.

\subsection{Infra-orbitais, Nasal e Antorbital}

Supra-orbital ausente. Infra-orbitais 1 a 6 presentes; sendo o 6 o menor e o 3 o maior; infraorbitais 2 e 3 com grande interseção. Canal latero-sensorial na porção interna de todos os infra-orbitais; infra-orbitais 4 e 5 com o canal um pouco deslocado para a porção central do osso. Nasal bastante delgado e côncavo posteriomente. Antorbital em formato de ampulheta, mais largo ventralmente (Fig. 5).

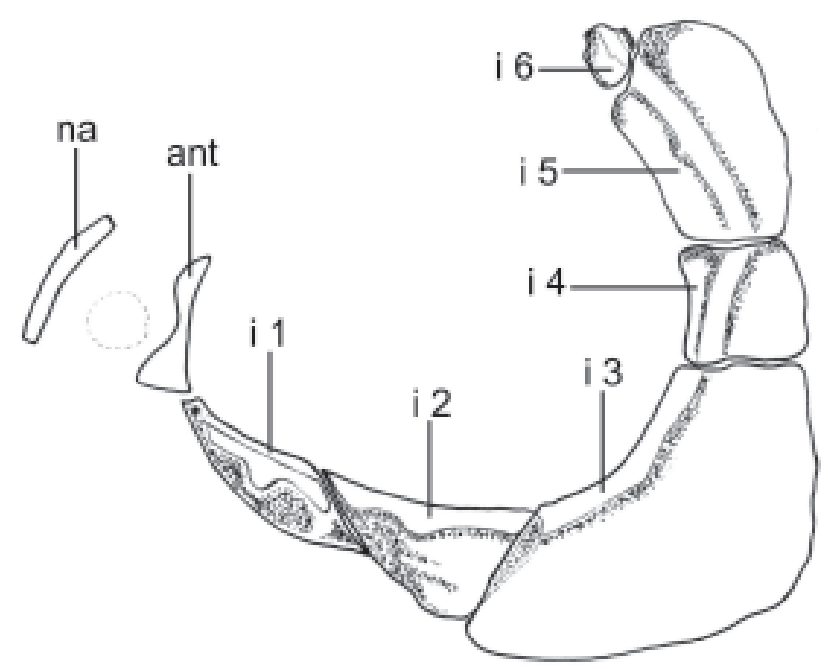

Fig. 5- Bryconamericus exodon, MZUSP 28026, 43,1 mm CP, vista lateral dos infra-orbitais, nasal e antorbital. Escala, 0,5 $\mathrm{mm}$.

Fig. 5- Bryconamericus exodon, MZUSP 28026, 43,1 mm SL, infraorbital series, nasal and antorbital, lateral view. Scale bar, 0,5 mm. 


\subsection{Maxilas}

Pré-maxilar com duas séries de dentes; série externa com 4 a 6 dentes tricuspidados; série interna com 4 dentes tetra, penta ou hexacuspidados alinhados e maiores que os da série externa. Série externa desalinhada; em exemplares com 4 dentes, o primeiro e o quarto são mais projetados anteriormente; em exemplares com 5 dentes, o primeiro e o quinto ou o primeiro, o terceiro e o quinto são mais projetados anteriormente; em exemplares com 6 dentes, o primeiro e o sexto ou o primeiro, o terceiro, o quinto e o sexto são mais projetados anteriormente. Maxilar com a porção anterior mais delgada; dois a três dentes tricuspidados ou cônicos localizados na altura ou pouco abaixo da altura do pré-maxilar; porção posterior mais larga, estendendo-se até a metade do infra-orbital 2. Dentário relativamente curto, com a região mediana mais elevada e 12 a 15 dentes em uma única série; os quatro anteriores, maiores, tetra, penta ou hexacuspidados, seguidos por 8 a 11 dentes menores, tricuspidados ou cônicos (os últimos). Osso corono-meckeliano bem desenvolvido e com apenas uma pequena porção ventral encoberta pela cartilagem do ânguloarticular, quando em vista medial (Figs. 6 e 7).

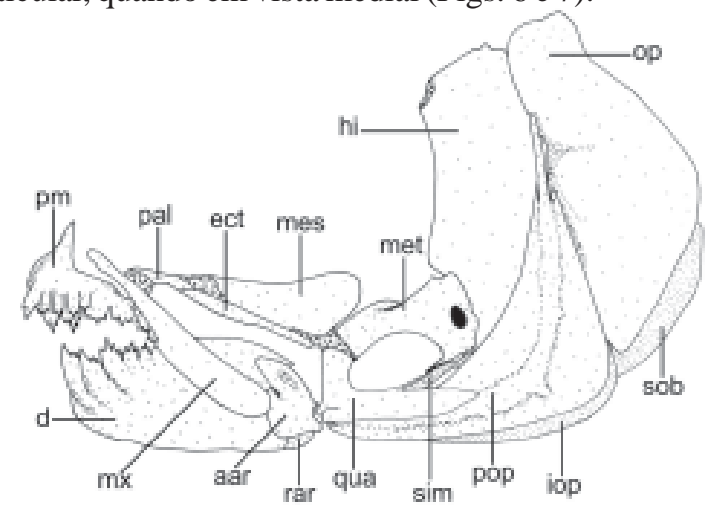

Fig. 6- Bryconamericus exodon, MZUSP 28026, 43,1 mm CP, vista lateral das maxilas, suspensório e ossos operculares. Escala, $1 \mathrm{~mm}$. Fig. 6- Bryconamericus exodon, MZUSP 28026, 43,1 mm SL, upper and lower jaws, suspensorium and opercular bones, lateral view. Scale bar, $1 \mathrm{~mm}$.

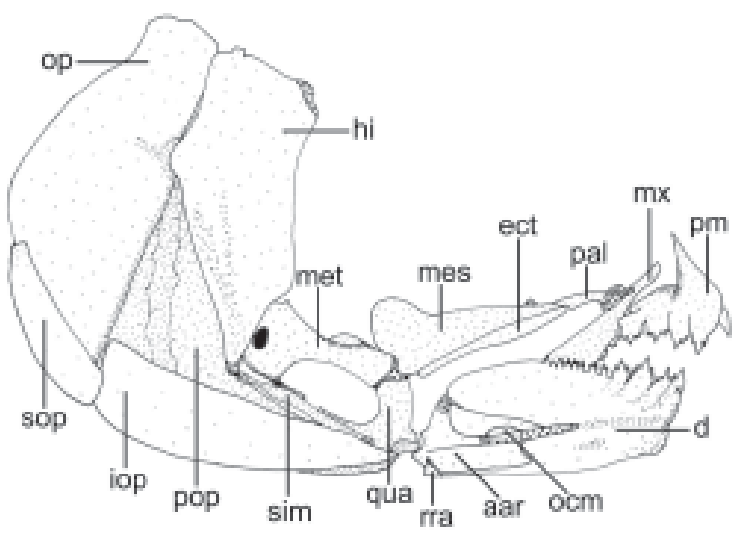

Fig. 7- Bryconamericus exodon, MZUSP 28026, 43,1 mm CP, vista medial das maxilas, suspensório e ossos operculares. Escala, $1 \mathrm{~mm}$. Fig. 7- Bryconamericus exodon, MZUSP 28026, 43,1 mm SL, upper and lower jaws, suspensorium and opercular bones, medial view. Scale bar, $1 \mathrm{~mm}$.

\subsection{Suspensório}

Palatino retangular, longo e com uma fenestra anterior, deslocada em direção medial. Mesopterigóide com formato aproximado de um triângulo, a região anterior mais estreita e a posterior mais alta, não contactando o quadrado ventralmente. Ectoperigóide alongado, a região anterior mais alargada e a posterior pontiaguda e separada do quadrado por um pequeno espaço. Quadrado longo, mais alto anteriormente. Simplético delgado, com aproximadamente a mesma largura em toda a sua extensão, estendendo-se desde pouco depois da extremidade anterior do interopérculo até o hiomandibular. Metapterigóide estreito anteriormente e alto posteriormente, com uma projeção óssea laminar dorsal pouco desenvolvida, próximo ao mesopterigóide e uma pequena invaginação póstero-dorsal, próximo à união com o hiomandibular. Anteriormente ao metapterigóide há uma grande porção cartilaginosa unindo-o ao mesopterigóide, ectopterigóide e quadrado; posteriormente o metapterigóide apresenta uma fenestra mediana, próximo ao hiomandibular e liga-se por cartilagem à metade posterior do simplético e região ântero-ventral do hiomandibular; mais dorsalmente apresenta região de intersecção com aquele osso. Hiomandibular aproximadamente retangular até a região de contato com o metapterigóide, depois afila para terminar em uma projeção arredondada, próximo à porção posterior do simplético. Pré-opérculo não ultrapassa as margens dorsais do opérculo e hiomandibular; canal sensorial na região mediana do osso. Interopérculo aproximadamente triangular, estendendo-se do limite entre quadrado e ângulo-articular, anteriormente, até o contato entre opérculo e subopérculo, posteriormente. Opérculo com uma leve concavidade posterior e dorsal e ligeiramente inclinado para a frente. Subopérculo curto, terminando pouco antes do final da base do opérculo (Figs. 6, 7 e 8).

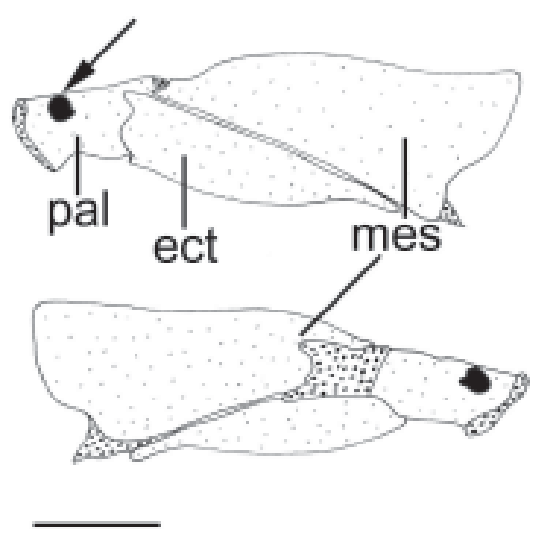

Fig. 8- Bryconamericus exodon, MZUSP 28026, 43,1 mm CP, ectopterigóide, mesopterigóide e palatino, respectivamente vista medial e lateral; seta indica fenestra. Escala, $1 \mathrm{~mm}$.

Fig. 8- Bryconamericus exodon, MZUSP 28026, 43,1 mm SL, ectopterygoid, mesopterygoid and palatine, medial and lateral view respectively; arrow points the fenestra. Scale bar, $1 \mathrm{~mm}$. 


\subsection{Arco Hióide e Arcos Branquiais}

Cerato-hial posterior com uma fenestra alongada e mediana. Quatro raios branquiostégios. Basi-hial triangular e alongado; porção anterior aproximadamente duas vezes mais larga que a posterior. Basibranquiais sinuosos; o primeiro com a porção anterior mais larga que a posterior, os demais aproximadamente com a mesma largura em toda a extensão. Hipobranquiais cerca de 1/3-1/4 do comprimento dos ceratobranquiais. Hipobranquial 3 e ceratobranquial 4 com projeções ósseas ântero-dorsais bastante delgadas. Placa dentígera do ceratobranquial 5 triangular. Rastros branquiais setiformes, com cteniis presentes apenas na base dos epibranquiais, que equivalem à metade do comprimento daqueles dos ceratobranquiais. Primeiro arco branquial com 2 a 3 rastros no hipobranquial, 7 a 9 no ceratobranquial e 5 a 8 no epibranquial, às vezes 1 rastro nas junções entre 0 hipobranquial e o ceratobranquial e entre esse e o epibranquial. Ceratobranquiais 3 e 4 e epibranquiais 1 a 3 com duas séries de rastros. Faringo-branquial 1 bastante reduzido e triangular, o 2 e 3 delgados e longos, o 3 com alguns dentes anteriores à placa dentígera formada pelos epibranquial e faringobranquial 4 . Porção anterior do urohial com uma bifurcação anterior e duas pequenas projeções laterais e posteriores; na porção mais posterior há abas laterais mais curtas e um grande prolongamento do eixo médio mais ventral (Figs. 9 e 10)

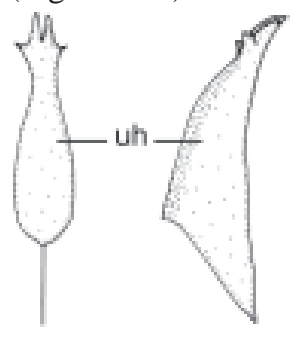

Fig. 9- Bryconamericus exodon, MZUSP 28026, 43,1 mm CP, urohial. Escala, $1 \mathrm{~mm}$.

Fig. 9- Bryconamericus exodon, MZUSP 28026, 43,1 mm SL, urohyal. Scale bar, $1 \mathrm{~mm}$.

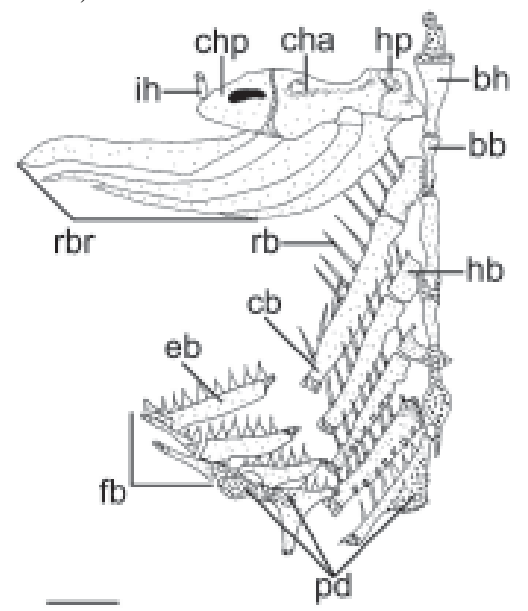

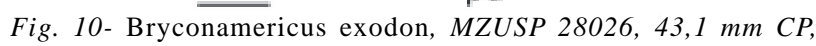
arcos branquiais e arco hióide, vista dorsal. Escala, $1 \mathrm{~mm}$.

Fig. 10- Bryconamericus exodon, MZUSP 28026, 43,1 mm SL, branchial and hyoid archs, dorsal view. Scale bar, $1 \mathrm{~mm}$.

\subsection{Aparelho de Weber}

Complexo neural aproximadamente triangular, com a base voltada para os arcos neurais 3 e 4; região ântero-ventral convexa e região póstero-dorsal côncava. Arco neural 3 com um processo dorsal, sobreposto parcialmente ao complexo neural, e um processo transverso estendido ao escáfio, ovalado e ligeiramente alongado horizontalmente. Intercalário bastante delgado em vista lateral. Arco neural 4 com um grande entalhe posterior e com espinho neural curto, estendendo-se pouco além da porção posterior do complexo neural. Centro vertebral 1 quase totalmente visível em vista lateral, com apenas uma pequena região encoberta pelo processo lateral do centro vertebral 2 e pelo trípode. Centro vertebral 2 com apenas uma pequena região visível lateralmente. Processo lateral do centro vertebral 2 delgado, abaixo do trípode. Trípode triangular e amplo, com uma projeção delgada, posterior e medial à primeira costela pleural curta e larga. Cinco a sete supraneurais, desde o aparelho de Weber até a nadadeira dorsal, o primeiro supraneural (associado ao arco neural 4) muito reduzido ou ausente (Fig. 11).

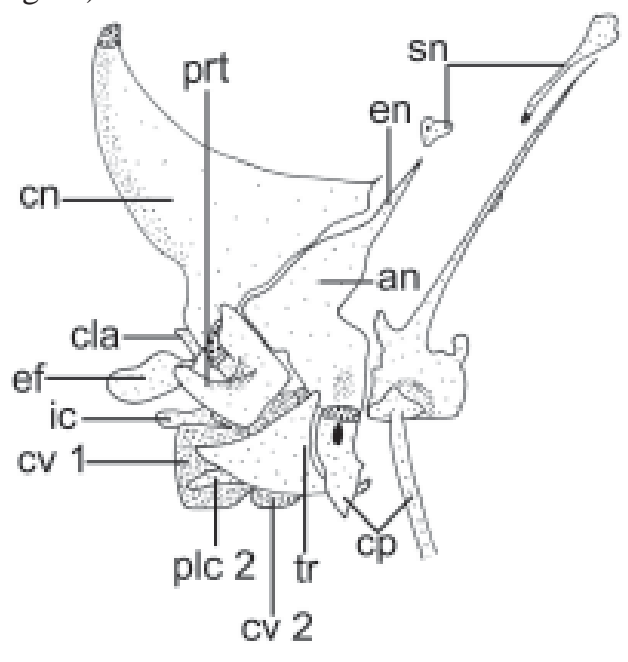

Fig. 11- Bryconamericus exodon, MZUSP 28026, 43,1 mm CP, aparelho de Weber. Escala, $1 \mathrm{~mm}$.

Fig. 11- Bryconamericus exodon, MZUSP 28026, 43,1 mm SL, Weberian apparatus. Scale bar, $1 \mathrm{~mm}$.

\subsection{Cintura e Nadadeira Peitoral}

Coracóide com aproximadamente a mesma altura em toda a sua extensão, formando uma fenestra grande e ovalada com o cleitro. Cleitro levemente inclinado para a frente. Supracleitro com uma projeção globosa, posterior, próximo ao pós-temporal, e um processo dorsal que contacta o pós-temporal medialmente. Pós-temporal largo ventralmente, afilando progressivamente e terminando em ponta. Pós-cleitro 1 globoso, ligado à porção mais posterior do supracleitro e separado dos demais componentes da série. Pós-cleitro 2 ovalado, ligado à região mais poste-

http://www.biotaneotropica.org.br 
rior do cleitro. Pós-cleitro 3 longo e sinuoso, sem projeção posterior, disposto entre o pós-cleitro 2 e a escápula e estendendo-se até a linha horizontal que passa pela margem ventral do coracóide. Escápula bifurcada dorsalmente em um ramo mais retangular, anterior, ligado ao cleitro por uma porção cartilaginosa e outro mais arredondado, posterior. Mesocoracóide delgado e com a base larga. Nadadeira peitoral com i, 10-12 raios (Figs. 12 e 13).

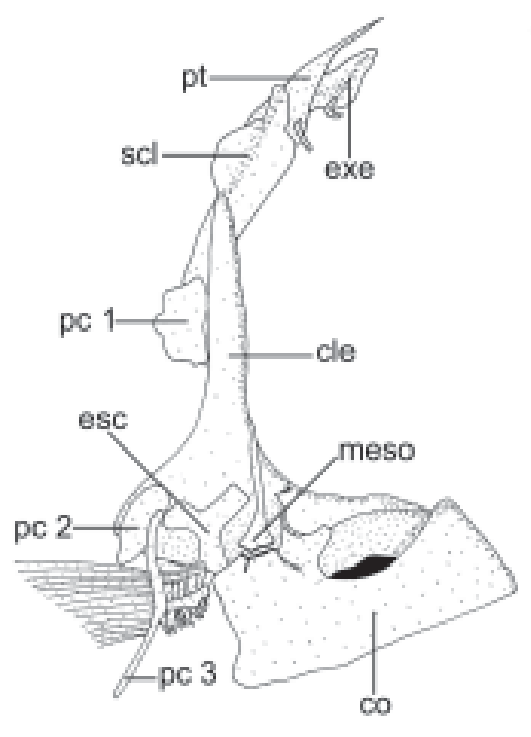

Fig. 12- Bryconamericus exodon, MZUSP 28026, 43,1 mm CP, vista medial da cintura peitoral e nadadeira. Escala, $1 \mathrm{~mm}$.

Fig. 12- Bryconamericus exodon, MZUSP 28026, 43,1 mm SL, pectoral girdle and fin, medial view. Scale, $1 \mathrm{~mm}$.

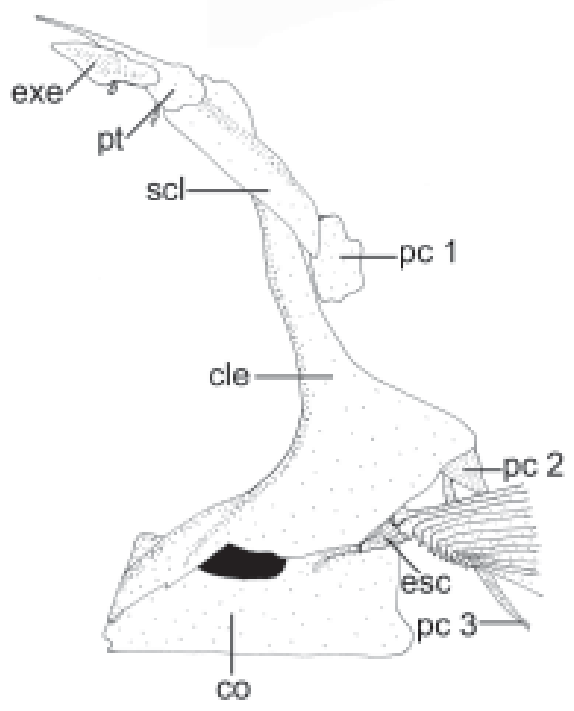

Fig. 13- Bryconamericus exodon, MZUSP 28026, 43,1 mm CP, vista lateral da cintura peitoral e nadadeira. Escala, $1 \mathrm{~mm}$.

Fig. 13- Bryconamericus exodon, MZUSP 28026, 43,1 mm SL, pectoral girdle and fin, lateral view. Scale bar, $1 \mathrm{~mm}$.

\subsection{Cintura Pélvica e Nadadeira}

Osso pélvico aproximadamente triangular. Processo isquiático projetando-se dorsalmente e em seguida ventralmente, formando, um V invertido e com a extremidade posterior cartilaginosa. Nadadeira pélvica com i, 7 raios (Fig. 14). Raios da nadadeira pélvica apresentando ganchos ósseos durante o período reprodutivo.

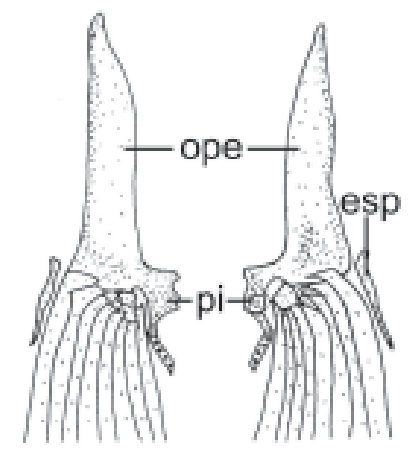

Fig. 14- Bryconamericus exodon, MZUSP 28026, 43,1 mm CP, respectivamente vistas lateral e medial da cintura pélvica e nadadeira. Escala, $1 \mathrm{~mm}$.

Fig. 14- Bryconamericus exodon, MZUSP 28026, 43,1 mm CP, pelvic girdle and fin, lateral and medial view, respectively. Scale bar, $1 \mathrm{~mm}$.

\subsection{Nadadeiras Dorsal, Anal e Caudal}

Primeiro radial proximal da nadadeira dorsal amplo e trifurcado anteriormente; demais radiais proximais simples e mais delgados, diminuindo progressivamente de tamanho em direção posterior. Nadadeira dorsal com ii, 8 raios. Nadadeira anal longa, com iii-iv, 20-24 raios; primeiro radial proximal mais longo sustenta os dois ou três primeiros raios simples; os demais radiais proximais progressivamente mais curtos em direção posterior; primeiro raio ramificado longo, os outros progressivamente menores em direção posterior. Raios da nadadeira anal apresentando ganchos ósseos durante o período reprodutivo. Nadadeira caudal com sete hipurais, o primeiro e o segundo (fundidos e separados do centro composto) e o quarto são mais largos que os demais. Processo neural especializado bem desenvolvido, terminando em ponta e projetando-se entre o último espinho neural e o primeiro epural. Nadadeira caudal com 10 raios superiores principais e 9 raios inferiores principais (Figs. 15-17). 


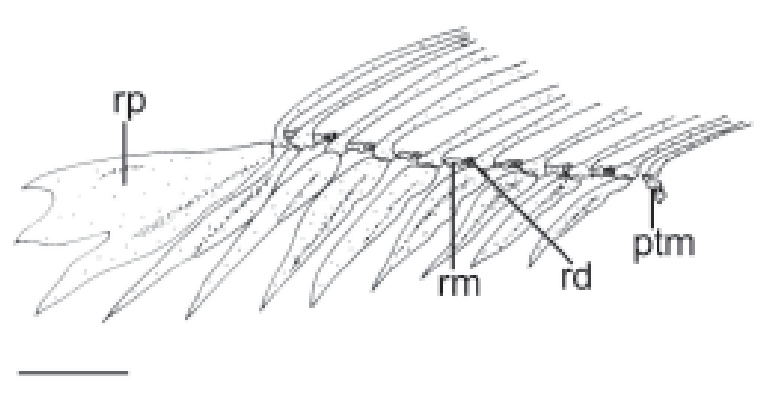

Fig. 15 Bryconamericus exodon, MZUSP 28026, 43,1 mm CP, nadadeira dorsal. Escala, $1 \mathrm{~mm}$.

Fig. 15 Bryconamericus exodon, MZUSP 28026, 43,1 mm SL, dorsal fin. Scale bar, $1 \mathrm{~mm}$.

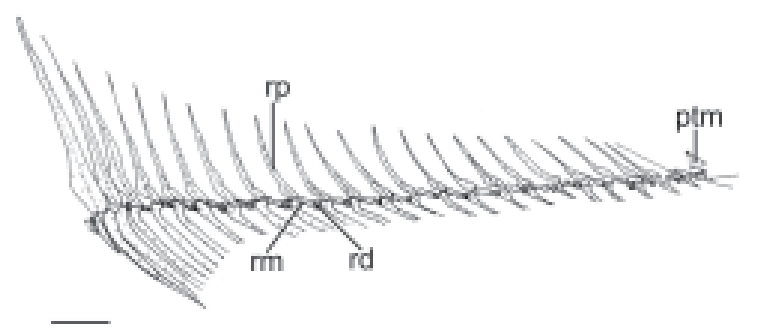

Fig. 16- Bryconamericus exodon, MZUSP 28026, 43,1 mm CP, nadadeira anal. Escala,1 $\mathrm{mm}$.

Fig. 16- Bryconamericus exodon, MZUSP 28026, 43,1 mm SL, anal fin. Scale bar, $1 \mathrm{~mm}$.

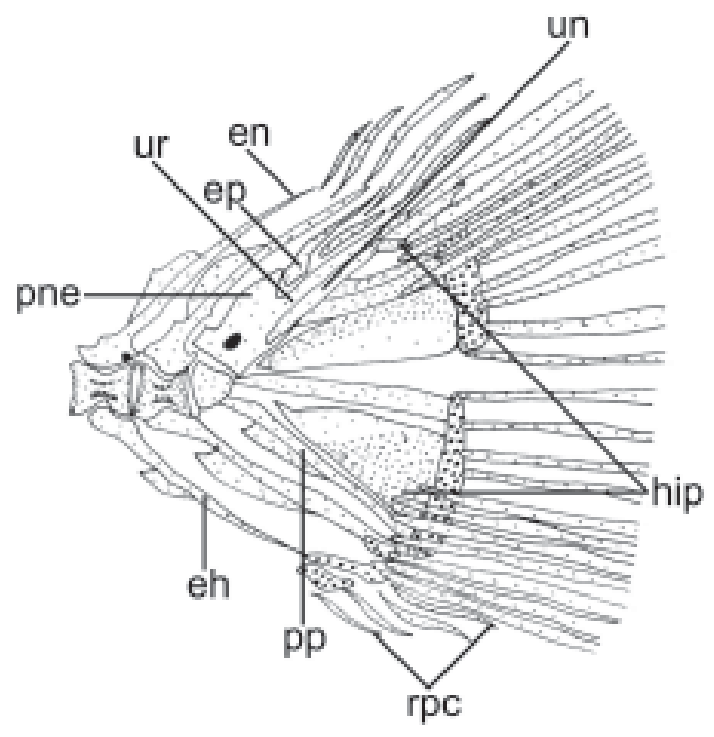

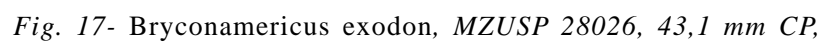
nadadeira caudal. Escala, $1 \mathrm{~mm}$.

Fig. 17- Bryconamericus exodon, MZUSP 28026, 43,1 mm SL, caudal fin. Scale bar, $1 \mathrm{~mm}$.

\section{Discussão}

Bryconamericus apresenta uma série de caracteres amplamente distribuídos em Characidae, o que leva à inexistência de uma definição clara para o gênero e contribui para o agrupamento de um grande número de espécies para as quais não existe nenhuma hipótese de monofiletismo. A idéia corrente é a de que Bryconamericus, na definição atual, não represente um grupo monofílético (Vari \& Siebert 1990; Malabarba \& Malabarba 1994; Lima et al. 2003) e, por isso, abrigue espécies mais relacionadas filogeneticamente a outros subgrupos e gêneros de Characidae.

Embora nossos resultados não tenham revelado nenhum estado apomórfico inequívoco para Bryconamericus exodon e todas as demais espécies do gênero examinadas, alguns caracteres merecem comentários por permitirem e corroborarem hipótese de relacionamento filogenético do gênero dentro de Characidae, bem como sugerirem subgrupo de Bryconamericus potencialmente monofilético.

O palatino na grande maioria dos Characiformes é um osso relativamente retangular, com aproximadamente a mesma espessura em toda a sua extensão, inteiriço e sem nenhuma fenestra ou perfuração. Bryconamericus exodon, contudo, possui uma fenestra grande, anterior e medial no palatino. Fenestra semelhante ocorre em B. caucanus, B. stramineus, Hemibrycon boquiae, Odontostoechus lethostigmus, Piabina argentea, Rhinobrycon negrensis e Planaltina britskii. Outras espécies examinadas, B. turiuba, Bryconamericus sp. (rio São Francisco), Carlastyanax aurocaudatus, Mimagoniates microlepis e Pseudocorynopoma heterandria, apresentam uma perfuração pequena, ou um adelgaçamento, na mesma porção do palatino, condições homólogas e apomórficas em Characiformes.

Bryconamericus exodon e as demais espécies citadas compartilham ainda a posse de ii, 8 raios na nadadeira dorsal e quatro dentes na série externa do prémaxilar, estados apomórficos propostos por Malabarba \& Weitzman (2003) para o subgrupo monofilético de Characidae denominado Clado A (Malabarba \& Weitzman 2003, fig. 2). Dentro do Clado A, a posse de um palatino fenestrado, perfurado ou adelgaçado na porção anterior e medial ocorre em diversos de seus subgrupos, o que sugere que essas modificações no palatino possam ser consideradas uma sinapomorfia adicional para o grupo (o pequeno número de táxons examinados não permite a polarização dos estados do palatino). Fora do Clado A, Hyphessobrycon eques apresenta o palatino adelgaçado na mesma região da fenestra ou da perfuração; contrariamente aos membros daquele clado a espécie possui ii, 9 raios na nadadeira dorsal e cinco dentes na série interna do prémaxilar, o que sugere que as condições semelhantes no palatino em Hyphessobrycon eques e no Clado A sejam homoplásticas. 
O pós-cleitro 3, de forma geral, é um osso sinuoso, alongado e com aproximadamente a mesma largura em toda sua extensão, condição encontrada na maioria dos Characiformes. Dentro de Characidae, Serrasalmus, Cheirodontinae, Characinae, Stethaprioninae, Iguanodectinae e Tetragonopterinae (sensu Géry 1977, menos o Clado A) apresentam o pós-cleitro 3 modificado, com uma projeção convexa e posterior, condição apomórfica em Characiformes. Adicionalmente, Cheirodontinae, Characinae, Stethaprioninae, Iguanodectinae, Aphyocharacinae, Rhoadsiinae, Clado A, parte de Tetragonopterinae (sensu Géry, 1977) e mais alguns gêneros incertae sedis de Characidae compartilham a perda do supraorbital (Malabarba \& Weitzman 2003). Dentre os Characidae sem supra-orbital, contudo, condições diferentes relativas ao pós-cleitro 3 ocorrem em Aphyocharacinae,onde o pós-cleitro três é muito reduzido e em Bryconamericus exodon e nos demais Characidae do Clado A, onde o referido osso é alongado e com aproximadamente a mesma largura em toda sua extensão, igualmente à condição plesiomórfica em Characiformes. Isso permite interpretar a presença de um pós-cleitro 3 com uma projeção convexa posterior como sinapomorfia de Serrasalminae mais os Characidae que perderam o supraorbital, com uma reversão para um póscleitro simples, sem projeção convexa posterior, nos representantes do Clado $A$, sendo essa reversão uma sinapomorfia adicional para o clado.

Finalmente, além dos caracteres discutidos acima, $B$. exodon, junto com $B$. stramineus e $B$. turiuba, forma um grupo de espécies caracterizadas pela posse de uma combinação exclusiva de estados de caracteres: corpo relativamente baixo e alongado, sua altura menos de $30 \%$ do CP (vs altura mais de $30 \%$ do CP); boca terminal (vs boca sub-inferior); dentes da série externa do prémaxilar desalinhados (vs alinhados). A presença de um corpo baixo e alongado é uma característica de difícil interpretação, dada a diversidade existente em Characidae, o que sugere eventos de aquisição independente de um ou outro estado, bem como eventos de reversão. O desalinhamento dos dentes da série externa do pré-maxilar é provavelmente característica apomórfica, como já sugerido por Géry (1966) para os Hemibryconini; boca terminal, entretanto, é plesiomórfica em Characidae (ver comentários em Malabarba \& Vari, 2000 referentes ao desalinhamento dos dentes e boca terminal). A otimização desses estados de caráter dentro do Clado A, contudo, não pode ser feita de maneira inequívoca e apenas uma análise envolvendo um maior número de táxons e caracteres poderá corroborar essa hipótese de relacionamento filogenético entre essas espécies de Bryconamericus.

\section{Material Comparativo}

Alestes longipinnis: DZSJRP3795 (1d\&c. CP. 76,2 mm), ÁFRICA: Ghana, Takoradion, Tarkwa road, state loc. $30^{\circ}$ NW. Astyanax altiparanae: DZSJRP3297 (2 d\&c. CP. 48,8 e 51,4 mm),BRASIL: SP, Palestina, rio Turvo, Boturuna,
20¹7’17"S/49²9’8"W. Brycon sp: DZSJRP3803 (1d\&c. CP. 96,3 mm), BRASIL: MT, próximo a Colider, rio Teles Pires,

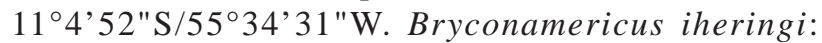
DZSJRP3318 (2 d\&c. CP. 42,6 e 45 mm), BRASIL: SP, riachos próximos à represa de Jurumirim, Bacia do rio Paranapanema, 2317’18"S/48³9'2"W. Bryconamericus microcephalus: DZSJRP4411 (2 d\&c. CP. 45,6 e 59 mm), BRASIL: SP, Iporanga, rio Betari. Bryconamericus stramineus: DZSJRP3429 (2 d\&c. CP. 43 e 52,7 mm), BRASIL: SP, Turiúba, Ribeirão Santa Bárbara, 2057’59"S/50¹'5"W. Bryconamericus turiuba: DZSJRP3914 (parátipo) (1 d\&c. CP. 53,4 mm), BRASIL: SP, Turiúba, Ribeirão Santa Bárbara, 2057’59"S/50¹'6"W. Bryconamericus sp: DZSJRP3022 (2 d\&c. CP. 30,7 e 35 mm), BRASIL: GO, Caldas Novas, Rio Quente (nascente), afluente do rio Corumbá, afluente do rio Paranaíba, alto rio Paraná, 1743’14"S/48³4’32"W; DZSJRP4350 (2 d\&c. CP. 40 e 45,2 mm), BRASIL: MG, São Roque de Minas, Rio São Francisco. Bryconops sp: DZSJRP3804 (2 d\&c. CP. 55,7 e 75,4 mm), BRASIL: MT, Colider, córrego Fortuna, afluente do rio Teles Pires, 1058'55"S/55³2’20"W. Carlastyanax aurocaudatus: DZSJRP6638 (1 d\&c. CP. 46,6 mm), COLOMBIA: Quindio, Alto Cauca, quebrada La Siria, afluente do Rio Roble, virada La Siria, Circasia. Coptobrycon bilineatus: DZSJRP6890 (2 d\&c. CP. 28,1 e 36,3 mm), BRASIL: SP, Bertioga, desembocadura de riacho afluente da margem direita do rio Itatinga, $5^{\mathrm{a}}$ ponte de madeira na estrada de terra saindo do centro de visitantes do Parque das Neblinas, 2347'17.7"S/ 46¹1'26"W. Creagrutus britskii: MZUSP55232 (2 d\&c. CP. 35,1 e 38,6 mm), BRASIL: GO, São Domingos, rio da Lapa, a $500 \mathrm{~m}$ do sumidouro na Lapa Terra Ronca, Parque Estadual de Terra Ronca. Creagrutus ignotus: MZUSP61083 (2 d\&c. CP. 39,4 e 44,2 mm), BRASIL: MT, Nova Mutum, córrego sem nome, fazenda Buriti, cerca de $1,5 \mathrm{Km}$ ao sul da sede da fazenda, 1351'52"S/56¹1'36"W. Creagrutus menezesi: MZUSP76307 (2 d\&c. CP. 46,0 e 54,0 mm), BRASIL: GO, Minaçu, riacho à montante dos pilares da ponte do Rubão, margem direita, Serra da Mesa. Ctenobrycon cf. hauxwellianus: DZSJRP2803 (2 d\&c. CP. 32,1 e $37 \mathrm{~mm}$ ), BRASIL: MS, Miranda, Morro do Azeite, fazenda Bodoquena, 207'1"S/5644'47"W. Deuterodon iguape: DZSJRP2051 (2 d\&c. CP. 35,7 e 44,2 mm), BRASIL: SP, Pariquera-Açu, Cedaval-Setor Sul, riacho cercando arrozal alagado, Br 116, Km 461. Gymnocorymbus ternetzi: DZSJRP2808 (2 d\&c. CP. 30,4 e 37,4 mm), BRASIL: MS, Miranda, Morro do Azeite, fazenda Bodoquena, 207’1"S/ 5644'47"W. Hasemania melanura: FMNH54385 (2 d\&c. CP. 28,2 e 30,2 mm), BRASIL: PR, Porto União, rio Iguaçu, 28/xii/1908 (col. JDHaseman) (parátipos). Hasemania hanseni: MZUSP35676 (2 d\&c. CP. 21,8 e 33,0mm.), BRASIL: DF, Planaltina, córrego Pipiripau, perto de Planaltina, 2050"'S/4940"'W. Hasemania nana: MZUSP39171 (1 d\&c. CP. 25,5 mm), BRASIL: MG, ribeirão do gado, afluente do rio São Francisco, projeto UHE Formoso. Hasemania nana: MZUSP39184 (2 d\&c. CP. 19,4-23,8 mm), BRASIL: MG, córrego Gameleira, afluente do São Francisco, projeto UHE 
Formoso. Hemibrycon boquiae: DZSJRP6636 (1 d\&c. CP. $52 \mathrm{~mm})$, COLOMBIA: Alto Cauca, quebrada Boquia, afluente Rio Quindio. Hemigrammus marginatus: DZSJRP4762 (2 d\&c. CP. 25,5 e 29,7 mm), BRASIL: SP, Teodoro Sampaio, rio Paranapanema, 22³6'45,7’'S, 52¹5'19,5’'W. Hemigrammus unilineatus: MZUSP65409 (1 d\&c. CP. 25,7 mm), SURINAME: Distrito Brokopondo, Maykaboeka Creek, Gros Rosebel Area, Area de concessão Golden Star, 54’45"N/ 55¹6’9"W. Hollandichthys sp: DZSJRP5157 (1 d\&c. CP. 76,8 mm), BRASIL: sem dados de coleta,. Hyphessobrycon eques: DZSJRP4754 (3 d\&c. 27,3-29,5 mm), BRASIL: SP, Rosana, Usina Hidrelétrica de Rosana, rio Paranapanema

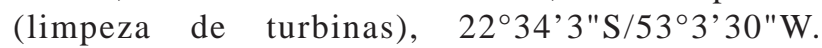
Hyphessobrycon negodagua: MZUSP54589 (4 d\&c. CP. 21,728,8 mm), BRASIL: BA, Iraquara, fazenda Pratinha, rio Pratinha, Parátipos, $12^{\circ} 21^{\prime} 13^{\prime \prime S} / 41^{\circ} 32^{\prime} 51^{\prime W}$. Knodus breviceps: DZSJRP6659 (1d\&c. CP: 66,5 mm), BRASIL: MT, Cuiabá, rio das Mortes, Km 314 da BR 364, São Vicente, afluente do rio Araguaia. Knodus moenkhausii: DZSJRP5131(4 d\&c. CP. 28,7-40,2 mm), BRASIL: SP, Dolcinópolis, ponte de concreto sobre o córrego da Prata, 20`9’32"S/50³1'4"W. Knodus sp: DZSJRP003062 (2 d\&c. CP. 40,2 e 42,5 mm), BRASIL: MT: Colider, córrego Fortuna, afluente do rio Carapá, rio Teles Pires, rio Tapajós. Knodus sp: DZSJRP003998 (2 d\&c. CP. 46 e 57,6 mm), BRASIL: MT: Alto Garças, ribeirão São Vicente, afluente do rio das Garças, Araguaia; DZSJRP6640 (1 d\&c. CP. 34,8 mm), COLOMBIA: Quindio, quebrada La Jaramilla, afluente do rio La Vieja, 300 m acima da ponte na estrada La Febaida. Markiana nigripinnis: DZSJRP355(2 d\&c. CP. 46,8 e 57,5 mm), BRASIL: MS, Miranda, Fazenda Bodoquena, Morro do Azeite, 207'2"S/5644'47"W. Metynnis maculatus: DZSJRP5499 (2 d\&c. CP. 35,7 e 42,2 mm), BRASIL, SP, Indiaporã, represa de Água Vermelha, próximo à cachoeira da fazenda Jandaia, rio Grande. Mimagoniates microlepis: DZSJRP5457 (2 d\&c. CP. 28,9 e 35,7 mm), BRASIL: SC, Mafra-Rio Negrinho, córrego Lajeado, cabeceira do rio Preto, drenagem do rio Iguaçu, 26³8'28.3"S/49³8'36.3"W. Moenkhausia sanctaefilomenae: DZSJRP3817 (2 d\&c. CP. 27 e $41 \mathrm{~mm}$ ), BRASIL: SP, Córrego da Barra Funda, drenagem do rio Preto. Odontosthoechus lethostigmus: DZSJRP7071 (1 d\&c. CP. 37,4 mm), BRASIL, RS, Tramandai, rio Três Forquilhas, Vila Boa União, 29³2'00',S/5005'00'”W. Oligosarcus sp: DZSJRP3824 (2 d\&c. CP. 36,9 e 54,3 mm), BRASIL: SP, Promissão, BR 153, próximo à estrada de Mendonça, sentido José Bonifácio. Parapristella aubynei: MZUSP17718 (1 d\&c. CP. 25,4 mm), BRASIL: RR, Boa Vista, Lagoa do Sr. Durval Magalhães, $47 \mathrm{Km}$ de Boa Vista, estrada Tepequém - Roraima, 250’N, 6040’W. Parapristella georgiae: MCP14922 (1 d\&c. CP. 30,7 mm), BRASIL: AM, Boa Vista, Confluência do rio Negro com o rio Urubaxi, drenagem do Alto rio Negro, 0³2’0"S/6450’0"W. Piabina argentea: DZSJRP443 (1 d\&c. CP. 45,2 mm), BRASIL: SP, Irapuã, Córrego afluente do rio Barra Mansa, afluente do rio Tietê, 21¹3’14"S/49¹9’3"W. Piabucus melanostomus:
DZSJRP620 (1 d\&c CP. 76 mm), BRASIL: Mato Grosso do Sul, Miranda, rio Miranda, Morro do Azeite, Fazenda Bodoquena, 207'2',S/5644'47'’W. Planaltina britskii: DZSJRP6298 (2 d\&c. CP. 32 mm [fêmea] e 33 mm [macho]), BRASIL: SP, Nova Aliança, ribeirão Borá, drenagem do rio Tietê, entre Nova Aliança e Potirendaba, 2101'18.1"S/ 49²7’34.6"W. Poptella paragayensis: DZSJRP627 (2 d\&c. CP 40 e 43.2 mm), BRASIL: Mato Grosso do Sul, Miranda, rio Miranda, Morro do Azeite, Fazenda Bodoquena, 207'2'S/56 44'47'”W. Pseudocorynopoma heterandria: DZSJRP6529(1 d\&c. CP. 39,6mm), BRASIL: SP, Biritiba Mirim, rio Biritiba Mirim, afluente do rio Tietê. Pseudocorynopoma heterandria: DZSJRP3253 (1 d\&c. CP. 33,8 mm), BRASIL: SP, Jacupiranga, fazenda Sambriú, Br 116, Km 471-472. Rhinobrycon negrensis: MZUSP27100 (2 d\&c. CP. 29,5 e 32,1 mm), BRASIL: AM, Manaus, rio Negro, acima de Manaus, $3^{\circ} 10^{\prime} \mathrm{S} / 60^{\circ} 0^{\prime} \mathrm{W}$. Roeboides paranensis: DZSJRP4761 (2 d\&c. CP. 40,8 e 41,8 mm), BRASIL: SP, Teodoro Sampaio, represa da Usina Hidrelétrica de Rosana, rio Paranapanema, 22³6’45,7'”S/52¹5'19,5”'S. Salminus hilarii: DZSJRP3833 (1 d\&c. CP. 74,8 mm), BRASIL: SP, divisa de Urupês e Irapuã, Córrego da Figueira, afluente do rio Cubatão ou Barra Mansa, 2111'28"S/49²3’37"W. Serrasalmus spilopleura: DZSJRP1903 (1 d\&c. CP 47,4 mm), BRASIL: SP, São José do Rio Preto, represa do Instituto Penal Agrícola. Tetragonopterus argenteus: DZSJRP3834 (2 d\&c. CP. 44,5 e 52 mm), BRASIL: MS, Miranda, Rio Miranda, Morro do Azeite, Fazenda Bodoquena, 207'2"S, 5644'47"W. Thayeria obliqua: MZUSP29391 (2 d\&c. CP. 34,2 e 34,6 mm), BRASIL: AM, confluência do rio Negro com o rio Urubaxi, $0^{\circ} 31^{\prime}$ S, 6450’W. Triportheus sp: DZSJRP4298 (1 d\&c. CP. 55 mm), BRASIL: Ouroeste, represa da UHE de Água Vermelha, rio Grande, Fazenda Jandaia, 2000'S e 50 22’W. Triportheus sp: DZSJRP623 (1 d\&c. CP. 49,9 mm), BRASIL: MS, Miranda, Morro do Azeite, fazenda Bodoquena, 207'1"S/5644'47"W. Xenurobrycon macropus: DZSJRP6641 (1d\&c. CP. 13,8 mm), BRASIL: MT, Nossa Senhora do Livramento, riacho da drenagem do rio Paraguai, na MT 060 (Cuiabá-Poconé).

\section{Agradecimentos}

J. Lundberg (ANSP), B. Chernoff (FMNH), C. Lucena (MCP), O. Shibatta (MZUEL), O. Oyakawa e J. Figueiredo (MZUSP) e C. Pavanelli (NUPELIA) disponibilizaram exemplares para análise e diafanização. O CNPq, Proc. 300474/99-7, e a FAPESP, Procs. 99/05193-2 e 04/00545-8(FL), 00/13872-6 (JPS, Iniciação Científica), e 02/05381-8 (JPS, Mestrado) financiaram a presente pesquisa.

\section{Referências Bibliográficas}

CASTRO, R.M.C. \& CASTRO, M.C. 1987. Proposta de uma nomenclatura osteológica para Characiformes (Pisces, Ostariophysi). Bol. Mus. Par. Emilio Goeldi, sér. Zool. 3:25-32. 
EIGENMANN, C.H., MCATEE, W.L. \& WARD, D.P. 1907. On further collections of fishes from Paraguay. Ann. Carn. Mus. 4:109-157.

EIGENMANN, C.H. 1927. The American Characidae. Mem. Mus. Comp. Zool. 43:311-428.

FINK, S.V. \& FINK, W.L. 1981. Interrelationships of the Ostariophysan fishes (Teleostei). Zool. J. Linn. Soc. London 72:297-353.

FINK, W.L. 1976. A new genus and species of characid fish from the Bayano river basin, Panamá (Pisces: Cypriniformes). Proc. Biol. Soc. Washington 88:331-244.

GÉRY, J. 1966. A review of certain Tetragonopterinae (Characoidei), with the description of two new genera. Ichthyologica / The Aquarium Journal 37:211-236.

GÉRY, J. 1977. Characoids of the world. T. F. H. Publications, Neptune City, New Jersey.

LANGEANI, F.; LUCENA, Z.M.S.; PEDRINI, J.L. \& TARELHO-PEREIRA, F.J. 2005. Bryconamericus turiuba, a new species from the upper Rio Paraná system (Ostariophysi, Characiformes). Copeia 2005:386-392.

LIMA, F.C.T., MALABARBA, L.R., BUCKUP,P.A., SILVA, J.F.P., VARI, R.P., HAROLD, A., BENINE, R., OYAKAWA, O., PAVANELLI, C.S., MENEZES, N.A., LUCENA, C.A.S., MALABARBA, M.C. S.L., LUCENA, Z.M.S., REIS, R.E., LANGEANI, F., CASATTI, L., BERTACO, V.A., MOREIRA, C. \& LUCINDA, P.H.F. 2003. Genera Incertae Sedis in Characidae. In Check List of Freshwater Fishes of South and Central America (R.E. Reis, S.O. Kullander \& C. J. Ferraris-Jr, orgs.). EDIPUCRS, Porto Alegre, p. 106-169.

MALABARBA, L.R. \& VARI, R.P. 2000. Caipobrycon tucurui, a new genus and species of characid from the rio Tocantins basin, Brazil (Characiformes: Characidae). Ichthyol. Explor. Freshwaters 11:315-326.

MALABARBA, L.R. \& WEITZMAN, S.H. 2003. Description of a new genus with six species from southern Brazil, Uruguay and Argentina, with a discusion of a putative characid clade (Teleostei: Characiformes: Characidae. Comun. Mus. Ciênc. PUCRS, sér. Zool. 16:67-151.

MALABARBA, M.C.S.L. \& MALABARBA, L.R. 1994. Hypobrycon maromba, a new genus and species of characiform fish from the upper rio Uruguai, Brazil (Ostariophysi: Characidae). Ichthyol. Explor. Freshwaters 5:19-24.

MONOD, T. 1967. Le complexe urophore des téléostéens: typologie et évolution (note preliminaire). Colloques Int. Cent. Natn. Rech. Scient. 163:11-31.

MONOD, T. 1968. Le complexe urophore des poissons téléostéens. Mém. Inst. Fond. Afr. Noire 81:1-34.

POTTHOFF, T. 1984. Clearing and staining techniques. In Ontogeny and systematics of fishes (H.G. Moser, W.J. Richards, D.M. Cohen, M.P. Fahay, A.W. Kendall-Jr, \& S.L. Richardson, eds.). American Society of Ichthyologists and Herpetologists, Lawrence, KA. p. 35-37.
REIS,R.E., KULLANDER, S.O.\&FERRARISJR., C.J., 2003(Eds.). Check list of the Freshwater Fishes of South and Central America(CLOFFSCA). EDIPUCRS, Porto Alegre. 729p.

ROMÁN-VALENCIA, C. 2000. Tres nuevas especies de Bryconamericus (Ostariophysi: Characidade) de Colombia y diagnóstico del género. Rev. Biol. Trop. 48:449-464.

VARI, R.P. 1983. Phylogenetic relationships of the families Curimatidae, Prochilodontidae, Anostomidae, and Chilodontidae (Pisces: Characiformes). Smith. Contr. Zool. Washington. 378:1-60.

VARI, R.P. \& HAROLD, A.S. 1998. The Genus Creagrutus (Teleostei: Characiformes: Characidae): monophyly, relationships, and undetected diversity. In Phylogeny and Classification of Neotropical Fishes (L.R. Malabarba, R.E. Reis, R.P. Vari, Z.M. Lucena \& C.A.S. Lucena, eds.). EDIPUCRS, Porto Alegre. p. 245-260.

VARI, R.P. \& HAROLD, A.S. 2001. Phylogenetic Study of the Neotropical fish genera Creagrutus Günter and Piabina Reinhardt (Teleostei: Ostariophysi: Characiformes), with a revision of the Cis-Andean species. Smith. Contr. Zool., Washington 613:1-239.

VARI, R.P. \& SIEBERT, D.J. 1990. A new unusually sexually dimorphic species of Bryconamericus (Pisces: Ostariophysi: Characidae) from the peruvian amazon. Proc. Biol. Soc. Washington 103:516-524.

WATROUS, L.E. \& WHEELER, W.D. 1981. The out-group comparison method of character analysis. Syst. Zool. 30:1-11.

WEITZMAN, S.H. 1962. The osteology of Brycon meeki, a generalized Characidae fish, with an osteological definition of the family. Stanford Ichthyol. Bull. 8:1-77.

WEITZMAN, S.H. 1974. Osteology and evolutionary relationships of the Sternoptychidae, with a new classification of stomiatoid families. Bull. Amer. Mus. Nat. Hist. New York 153:327-478.

WEITZMAN, S.H. \& MENEZES, N.A. 1998. Relationships of the Tribes and Genera of the Glandulocaudinae (Ostariophysi: Characiformes: Characidae) with a description of a new genus, Chrysobrycon. In Phylogeny and Classification of Neotropical Fishes (L.R. Malabarba, R.E. Reis, R.P. Vari, Z.M. Lucena \& C.A.S. Lucena, eds.) EDIPUCRS, Porto Alegre. p.171-192.

WEITZMAN, S.H.; MENEZES, N.A.; EVERS, H.-G \& BURNS, J.R. 2005. Putative relationships among inseminating and externally fertilizing characids, with a description of a new genus and species of Brazilian inseminating fish bearing and anal-fin gland in males (Characiformes: Characidae). Neotropical Ichthyology 3:329-360.

WEITZMAN, S.H. \& PALMER, L. 1997. A new species of Hyphessobrycon (Teleostei: Characidae) from the Neblina region of Venezuela and Brazil, with comments on the putative "rosy tetra clade”. Ichthyol. Explor. Freshwaters 7:209-242. 
Título: Redescrição e osteologia de Bryconamericus exodon Eigenmann, 1907 (Ostariophysi, Characiformes, Characidae).

Autores: Serra, J.P. and Langeani, F.

Biota Neotropica, Vol.6 ( número 3): 2006

http://www.biotaneotropica.org.br/v6n3/pt/ abstract?article+bn01906032006

Recebido em 19/04/05 - Versão revisada recebida em 03/07/06 - Publicado em 22/09/06

ISSN 1676-0603 